\title{
Effect of reduced or zero pin length and anvil insulation on friction stir spot welding thin gauge 6111 automotive sheet
}

\author{
D. Bakavos and P. B. Prangnell*
}

Friction stir spot welding (FSSW) is a relatively new process, which has not yet been fully optimised. The aim of the work presented was to investigate the influence of pin length and an insulating anvil on FSSW thin $(0.9 \mathrm{~mm}) 6111-\mathrm{T} 4$ aluminium automotive closure panels. A pinless, or 'zero pin length', tool was also tested. With a normal pin tool and a steel anvil the optimum pin length was found to be considerably shorter than conventionally used, being in the range $0 \cdot 7-$ $1 \mathrm{~mm}$, as opposed to $\sim 1.4 \mathrm{~mm}$. The insulated anvil increased the peak temperature in the bottom sheet by $45^{\circ} \mathrm{C}$, but there was a $15 \%$ reduction in lap shear strength when used with a conventional pin tool. In the case of the pinless tool, successful welds were produced with comparable strengths to the highest values measured with the optimum conventional tool without a retained weld keyhole or top sheet thinning (hooking).

Keywords: Friction stir spot welding, Pinless tool, AA6111, Thermal control, Shear strength, Lap joints

\section{Introduction}

There are clear pressures in the transport sector to move towards lower fuel consumption through the introduction of more weight efficient designs, involving the substitution of light alloys for steel and the greater use of multimaterial structures. It is also desirable in the current climate to reduce production costs by decreasing the energy requirements of manufacturing processes. This has highlighted the need for more efficient methods for joining light alloys.

Sheet steel automotive body panels are conventionally joined by electrical resistance spot welding (RSW), which is a cheap and robust process. However, RSW is far more difficult and expensive to apply to light alloys owing to their high conductivity, low strength at temperature and tendency to degrade the electrodes. ${ }^{1,2}$ Alternative solutions under investigation by the automotive industry include; mechanical fastening, by selfpiercing rivets or clinching, adhesive bonding, and laser and gas tungsten arc welding, as well as the solid state techniques of ultrasonic spot and friction stir welding (FSW) and friction stir spot welding (FSSW). ${ }^{3-8}$ of these methods, fusion processes are limited by the poor weldability and high levels of distortion that are characteristic of aluminium alloys. ${ }^{4}$ Furthermore, although very effective, mechanical joining techniques like self-piercing rivets are associated with high consumable costs. In comparison, FSSW is a very promising energy efficient solid state welding process and can offer

Materials Science Centre School of Materials, The University of Manchester, Grosvenor Street, Manchester, M1 7HS, UK

*Corresponding author, email philip.prangnell@manchester.ac.uk significant benefits when it is used either by itself, or combined together with adhesive bonding. ${ }^{8,9}$ Ultrasonic spot welding also shows early promise. ${ }^{6}$

Friction stir spot welding owes its origin to linear FSW developed in 1991 by The Welding Institute. ${ }^{10}$ As a joining process it has several advantages over other point joining methods, including no consumable costs and far lower energy consumption relative to resistance spot welding. ${ }^{4,11}$ It has already been applied in industry by the Mazda Motor Corporation resulting in large energy and capital investment gains compared to RSW ( $\sim 90 \%$ energy savings and $40 \%$ investment reduction). ${ }^{4,12}$ A schematic illustration of the friction stir spot welding process is shown in Fig. 1a. In FSSW a high speed rotating tool, consisting of a shoulder with a probe/pin, is plunged into the upper sheet of a lap joint while an anvil supports the down force. The weld cycle typically lasts $1-4 \mathrm{~s}^{13-20}$ In FSSW the heated and softened material below the tool deforms plastically to very high strains, disrupting the oxide at the joint interface, so that a solid state bond can be formed between the upper and lower sheets. However, several problems remain with this technique. These include: the aesthetically undesirable keyhole produced by the tool probe that is retained in the joined parts 'lifting of the top sheet' near the edge of the weld, and the difficulty of obtaining a full metallurgical bond under the shoulder, leading to low strength failures by cleavage fracture along the join line. ${ }^{3,13-15}$ Thinning of the top sheet caused by upward flow near the pin as it penetrates the bottom sheet (some times referred to as 'hooking') is also normally found to reduce the joint strength, ${ }^{14,15,21}$ although exceptions have been reported to this general rule. $^{22}$ 
A number of groups have investigated optimisation of the FSSW technique by studying the effect of process variables, such as the FSSW tool design, role of the shoulder plunge depth, rotation speed, plunge rate, weld hold time, probe profile and heat input. ${ }^{14-21,23,24}$ The process has also been modelled by the finite element method (e.g. Ref. 25), in order to better understand the metal flow and heat distribution. Results published from this work have demonstrated that for a given sheet thickness there is an optimum combination of weld time/ tool rotation speed $\left(\mathrm{rev} \mathrm{min}^{-1}\right.$ ) and plunge depth that maximises the degree of bonding and gives the best lap shear strengths. Variants on the FSSW process have also been developed, such as the 'refill' technique with a two part actuated tool, which offers a competitive surface finish and possibly an improved lap shear strength. ${ }^{26-28}$

In one study Tozaki et al. ${ }^{19}$ have reported that increasing the pin length can improve weld shear strengths in 6061 alloy ( $2 \mathrm{~mm}$ thick sheet), which agrees with a pervious claim that the pin needs to penetrate the bottom sheet by $\sim 25 \%$ of its thickness to obtain maximum joint strength. ${ }^{29}$ Research by Mitlin et al., ${ }^{13}$ using the same 6111 alloy and $0.9 \mathrm{~mm}$ gauge sheet studied here, has investigated the effect of tool plunge depth on lap shear strength. They determined a maximum strength, when a $\sim 1.7 \mathrm{~mm}$ plunge was used. However, in this work an important factor was the shoulder plunge depth, because the pin length was kept constant $(1.4 \mathrm{~mm})$. Further studies by Lin et al. ${ }^{14,15}$ have concentrated on the effect of shoulder geometry. They found on welding the same 6111 alloy a concave tool shoulder increased the lap shear strength from 1.94 to $2 \cdot 5 \mathrm{kN}$, relative to a flat shoulder tool. Other workers have studied the influence of the pin cross-section profile. ${ }^{21,30}$ In addition, a pinless FSSW tool has been used to produce dissimilar aluminium to steel welds. ${ }^{31}$

However, overall there is still a relatively poor understanding of the effect of the tool pin length and thermal management of the heat distribution during FSSW on joint shear strength. For example, as heat is generated by the tool shoulder there is a large thermal gradient between the top and bottom of the weld and insulating the anvil could potentially result in a more uniform through thickness heat distribution, possibly improving bonding. Indeed, $\mathrm{Su}$ et al. have shown that when a mica clamp and anvil were used it increased the heat dissipated into the weld from $\sim 13$ to $50 \%{ }^{18}$ Additionally, with thin gauges the pin would be expected to become less important and a pinless tool could potentially produce an acceptable joint, as long as the deformation zone penetrates sufficiently into the bottom sheet to disperse the interfacial oxide layer. ${ }^{31}$ With a shallow shoulder plunge depth this would eliminate the undesirable residual keyhole. Finally, currently published data on FSSWs of standard 6xxx series automotive alloys like 6111 , with the exception of the work by Mitlin et al., ${ }^{13}$ includes little microstructural information on the effects of the weld thermal and deformation cycle on the parent material.

In this paper the authors have focussed on the role of two main variables in the FSSW process in thin $0.9 \mathrm{~mm}$ thick 6111-T4 automotive sheets, where the shoulder has a greater influence on the bond formed. Namely, the length of the tool pin with a constant shoulder plunge depth, and the effect of reducing heat loss through the

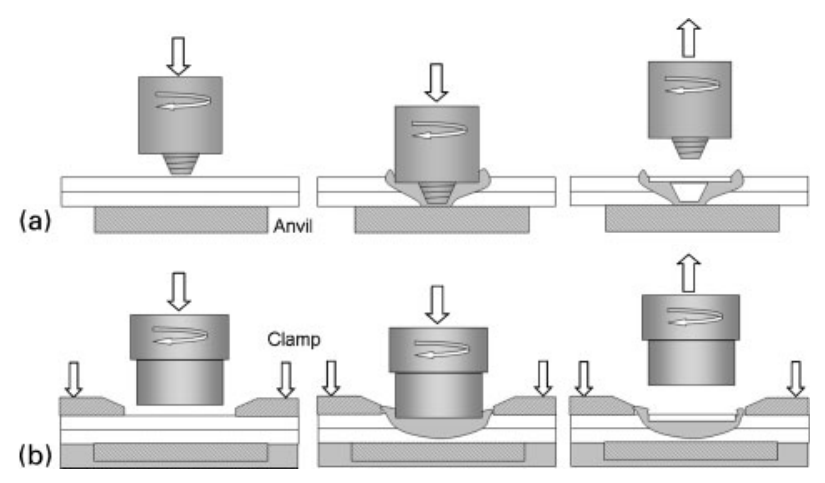

1 Schematic illustration of FSSW process, including top clamping system used in this work, with a conventional pin and $b$ novel pinless tool

bottom of the lower sheet by using an insulating material, rather than a conventional steel anvil. In addition the feasibility of using a pinless, or 'zero pin length', tool in thin sheet welding (Fig. 1b) has also been tested, as a simpler competitive technique to the FSSW refill approach. The authors have further attempted to correlate the pin length and thermal conditions to the weld energy input, and a detailed investigation of the nature of the bond formed, weld microstructure and the relationship to a joint's tensile lap shear performance.

\section{Experimental}

All the spot welds in this study were produced in $0.91 \mathrm{~mm}$ thick 6111-T4 aluminium alloy sheet, whose nominal composition was $\mathrm{Al}-0.9 \mathrm{Si}-0 \cdot 7 \mathrm{Cu}-0 \cdot 75 \mathrm{Mg}$ $0 \cdot 30 \mathrm{Mn}-0 \cdot 10 \mathrm{Cr}-0 \cdot 20 \mathrm{Fe}(\mathrm{wt}-\%)$. The sheet received no cleaning or surface preparation before joining. Welding trials were performed using a CS Powerstir friction stir welding machine. The welds were produced at the lap centre, on $25 \mathrm{~mm}$ by $100 \mathrm{~mm}$ strips with an overlap of $25 \mathrm{~mm}$, following the standard specimen geometry adopted elsewhere in similar research (e.g. Refs. 14 21). All spot welding was carried out under displacement control. The tool shoulder was $10 \mathrm{~mm}$ in diameter and manufactured from $\mathrm{H} 13$ tool steel, again selected to be consistent with the majority of previous studies (e.g. Refs. 13-20). The tool had a removable $10^{\circ}$ tapered triflat threaded pin with a diameter of $4 \mathrm{~mm}$, made from MP159 material. Six pin lengths were used in the investigation $0,0.7,1.0,1.21 .4$ and $1.6 \mathrm{~mm}$, with the $1.4 \mathrm{~mm}$ pin being comparable to tool designs most commonly reported in the literature for this sheet thickness (e.g. Refs. 13-15). The 'zero' length pin was machined flush with the shoulder, to give a pinless tool. The shoulder was flat with a machined scroll. To control lifting of the top sheet at the edge of the tool shoulder, ${ }^{32}$ a tight fitting clamping plate was used with a $12 \mathrm{~mm}$ diameter machined hole, resulting in a clearance of $1 \mathrm{~mm}$ with respect to the tool shoulder (Fig. 1b).

Welding was performed under position control. The following parameters were kept constant during the FSSW trials; plunge rate $\left(2.5 \mathrm{~mm} \mathrm{~s}^{-1}\right)$, rotational speed

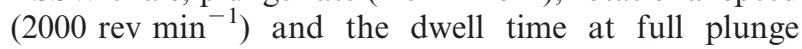
( $2.5 \mathrm{~s}$ ) (see Table 1$)$. The plunge depth was altered to obtain a constant shoulder penetration depth of $0.2 \mathrm{~mm}$, with the total tool penetration depth increasing with pin length. This shoulder plunge depth was selected 
following preliminary weld trials and was the minimum that could be used and produce good quality welds that failed by mode III fracture (see the section on 'Lap shear fracture behaviour'). During welding the temperature at the base of the weld was recorded by embedding a thermocouple vertically in the anvil. The thermocouple tip was mounted so that its tip protrude $\sim 0.1 \mathrm{~mm}$ above the anvil surface, ensuring good contact aided by the welding down force, and was positioned at the centre of the weld. Temperature measurements were repeated at least three times for each welding condition, with a maximum scatter of $\pm 5^{\circ} \mathrm{C}$. The weld energy (in $\mathrm{J}$ ) was calculated from integrating the torque curve, using the relationship

$$
U=\frac{2 \pi}{60} \omega \int_{\mathrm{t}_{0}}^{\mathrm{t}_{1}} T \mathrm{~d} t
$$

where $\omega$ is the rotational speed (in rev $\min ^{-1}$ ), $T$ is the torque and $t_{0}$ and $t_{1}$ are the tool contact and tool withdrawal times.

In order to study the influence of the through thickness thermal profile, generated during the welding cycle, two backing plates were used; a conventional steel anvil and an anvil laminated with an insulating $4 \mathrm{~mm}$ thick $25 \times 20 \times 4 \mathrm{~mm}$ Macor ceramic plate (thermal conductivity $=1.46 \mathrm{~W} \mathrm{~m}^{-1} \mathrm{~K}^{-1}$, compared to $52 \mathrm{~W} \mathrm{~m}^{-1} \mathrm{~K}^{-1}$ for steel).

To evaluate the mechanical strength of the joints, tensile lap shear tests were performed on each weld coupon using a constant displacement rate of $2 \mathrm{~mm} \mathrm{~min}^{-1}$. Results were averaged over three samples for each condition with the peak load being measured, as well as the total failure energy, by integration of the force displacement curves (see Fig. 2). The welded joints were sectioned to characterise the degree of bonding and weld zone microstructure. Microstructural analysis was performed using an Olympus optical microscope and a FEI Sirion field emission gun scanning electron microscope equipped with an HKL ${ }^{\mathrm{TM}}$ electron back scattered diffraction (EBSD) system and backscattered electron detector. The EBSD system had a spatial and angular resolution of $\sim 10 \mathrm{~nm}$ and $\sim 1^{\circ}$ respectively. ${ }^{33}$ To avoid misorientation noise, boundaries were cut-off at less than $1 \cdot 5^{\circ}$. The SEM samples were examined after light electropolishing to better reveal the bond line oxide residue. Microhardness profiles were measured for each weld by traversing across normal direction-rolling direction sections through the weld centres, $0.2 \mathrm{~mm}$ below the shoulder plunge depth and $0.2 \mathrm{~mm}$ from the bottom surface.
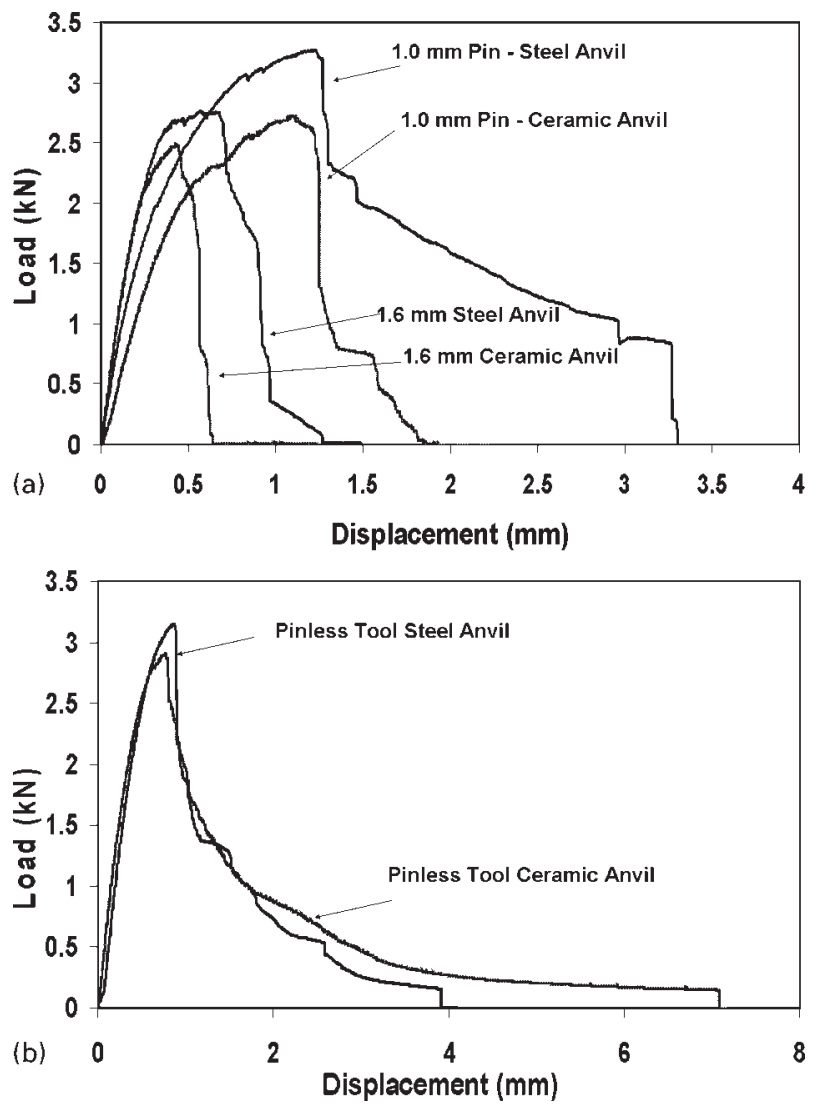

2 Example load displacement curves from lap shear tests, showing a behaviour for optimum $1.0 \mathrm{~mm}$ and longest $1.6 \mathrm{~mm}$ pin length tools studied and $b$ welds produced with pinless tool, both with steel and ceramic anvils

\section{Results and discussion}

\section{Lap shear performance}

Figure 2 shows examples of typical tensile lap shear test load displacement curves, while the average maximum shear loads and failure energies are summarised in Fig. 3, for all the welds performed with the standard $2.5 \mathrm{~s}$ dwell time. In Fig. 3 the shear strength for the welds produced with the ceramic anvil can be seen to decreases progressively with increasing pin length. Surprisingly, a zero pin length, or the pinless tool, gave the best results. In comparison the shear strength measurements for the steel anvil welds first increase slightly with pin length, to give an optimum strength at a pin length of about $0.7-1 \mathrm{~mm}$, before declining rapidly at longer pin lengths. However, the variability in weld

Table 1 Summary of spot welding parameters used in trials, with and without anvil insulation, including approximate weld energy calculated by integrating torque curves

\begin{tabular}{|c|c|c|c|c|c|c|c|c|}
\hline $\begin{array}{l}\text { Pin length, } \\
\mathrm{mm}\end{array}$ & $\begin{array}{l}\text { Plunge rate, } \\
\mathrm{mm} \mathrm{s}^{-1}\end{array}$ & $\begin{array}{l}\text { Tool rotation speed, } \\
\text { rev } \min ^{-1}\end{array}$ & $\begin{array}{l}\text { Dwell time, } \\
\text { s }\end{array}$ & $\begin{array}{l}\text { Weld time, } \\
\text { s }\end{array}$ & $\begin{array}{l}\text { Penetration } \\
\text { depth, mm }\end{array}$ & $\begin{array}{l}\text { Shoulder } \\
\text { plunge, mm }\end{array}$ & $\begin{array}{l}\text { Energy steel } \\
\text { anvil, kJ }\end{array}$ & $\begin{array}{l}\text { Energy ceramic } \\
\text { anvil, kJ }\end{array}$ \\
\hline Pinless & $2 \cdot 5$ & 2000 & $2 \cdot 5$ & 2.58 & $0 \cdot 2$ & 0.2 & $3 \cdot 1$ & $2 \cdot 8$ \\
\hline $0 \cdot 7$ & $2 \cdot 5$ & 2000 & $2 \cdot 5$ & $2 \cdot 86$ & 0.9 & 0.2 & $4 \cdot 6$ & $2 \cdot 9$ \\
\hline $1 \cdot 0$ & $2 \cdot 5$ & 2000 & $2 \cdot 5$ & 2.98 & $1 \cdot 2$ & $0 \cdot 2$ & $4 \cdot 8$ & $3 \cdot 6$ \\
\hline $1 \cdot 2$ & $2 \cdot 5$ & 2000 & $2 \cdot 5$ & $3 \cdot 06$ & $1 \cdot 4$ & 0.2 & $4 \cdot 0$ & $3 \cdot 7$ \\
\hline $1 \cdot 4$ & $2 \cdot 5$ & 2000 & $2 \cdot 5$ & $3 \cdot 14$ & $1 \cdot 6$ & $0 \cdot 2$ & $5 \cdot 0$ & $3 \cdot 8$ \\
\hline $1 \cdot 6$ & $2 \cdot 5$ & 2000 & $2 \cdot 5$ & $3 \cdot 22$ & $1 \cdot 8$ & $0 \cdot 2$ & $5 \cdot 1$ & 3.9 \\
\hline
\end{tabular}



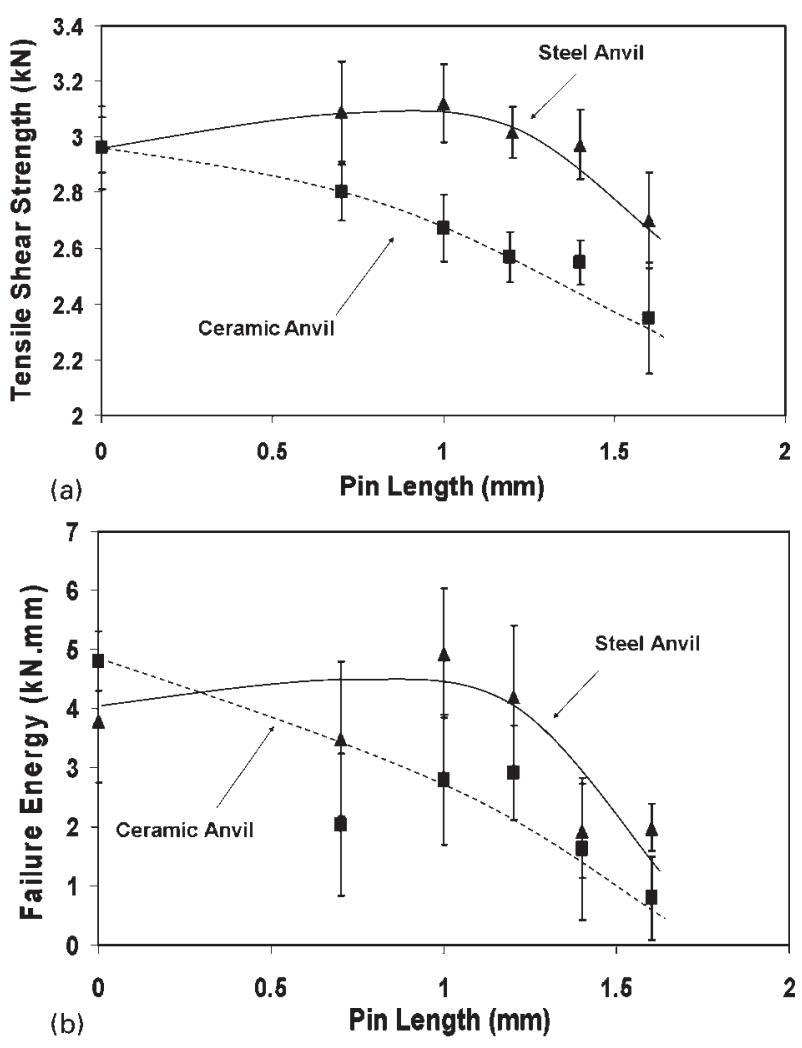

a shear strength; $b$ failure energy

3 Effect of pin length and anvil insulation on 6111 alloy sheet FSSW's $a$ tensile and $b$ failure energy

shear strength is relatively modest, with the strongest condition for the steel anvil having a shear strength of $3 \cdot 1 \mathrm{kN}$, compared to $2 \cdot 7 \mathrm{kN}$ for the weakest. Much more significant changes in performance can be noted when the failure energy is considered. When the steel anvil is used the integrated area under the shear test load displacement curves reduces from $\sim 5 \mathrm{kN} \mathrm{mm}^{-1}$, for the optimum pin length, to $1 \mathrm{kN} \mathrm{mm}^{-1}$ with the longest pin length used. This larger range of failure energies is caused by the strongest welds showing a far longer decay curve after reaching peak load, whereas the weaker welds failed more abruptly (see Fig. 2a).

Overall, the welds produced with a steel anvil always performed better than with a ceramic anvil, except for the case where a pinless tool was used, where the welds made with the insulated anvil had a similar (see Fig. 3). It is also interesting that in the shear tests the steel anvil welds gave an optimum performance at a shorter pin length compared to that usually used in the literature $(0 \cdot 7-1 \mathrm{~mm}$ as opposed to $1.4 \mathrm{~mm}) .{ }^{13-15}$ This optimum pin length was roughly equivalent to a penetration depth similar to the top sheet thickness. However, there was only a small reduction in strength relative to this condition when no pin was used at all (Fig. 3). In comparison, with a ceramic anvil the best result was achieved with a pinless tool, which gave nearly an identical shear strength to that with a steel anvil $(2 \cdot 9 \mathrm{kN})$, but a higher failure energy $(5 \cdot 1$ as opposed to $3 \cdot 9 \mathrm{kN} \mathrm{mm}^{-1}$ ).

The high performance of the welds made with the pinless tool is somewhat surprising, given that most previous work in the literature has assumed FSSW requires a tool with an integral probe that ideally penetrates to a depth of $\sim 25 \%$ of the bottom sheet. ${ }^{29}$

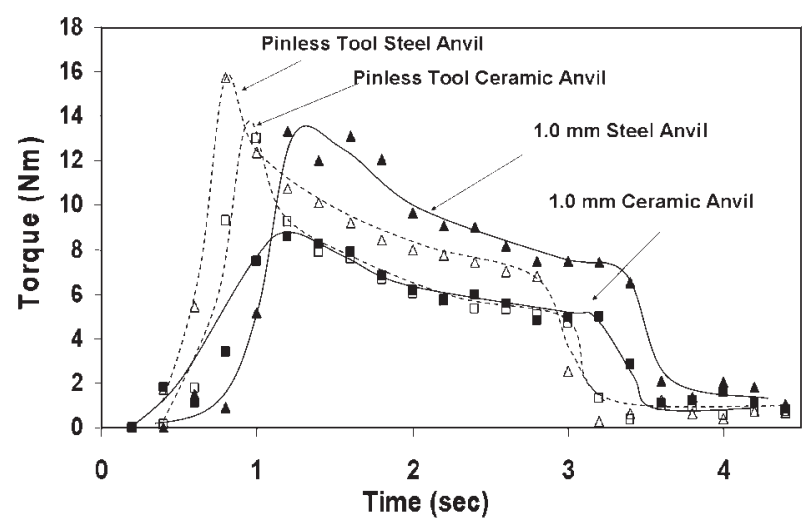

4 Example torque curves for conventional tool with $1.0 \mathrm{~mm}$ pin, as well as for pinless tool configuration, with different anvil materials

Furthermore, the lap shear strengths measured compare very favourably with those published in the literature using a conventional length pin tool, for welds produced in the same alloy, with a similar sheet gauge and tool shoulder diameter. Lin et al. ${ }^{14}$ report shear strengths of $1.94 \mathrm{kN}$ with a flat tool shoulder and $1.4 \mathrm{~mm}$ pin, with higher values of $2.59 \mathrm{kN}$ using a concave shoulder. ${ }^{15} \mathrm{In}$ comparison, Mitlin et al. ${ }^{13}$ report very similar values to those found here, with optimum shear strengths $\sim 3 \mathrm{kN}$. They also observed a slight reduction in strength for deep tool penetration. However, in their study the pin length was kept constant and they only altered the shoulder plunge depth. For thicker gauges, where the deformation caused by the pin is more important, contradictory results have been presented in a $2 \mathrm{~mm}$ 6061-T4 alloy sheet. For example, Tozaki et al. ${ }^{19}$ found that the weld shear strength increased with pin length, while Addison and Robelou ${ }^{29}$ report no significant change in weld strength as long as penetration of the lower aluminium panel was above $25 \%$ the sheet thickness.

\section{Weld energy and thermal measurements}

Example torque curves are shown in Fig. 4 for welds produced with a constant dwell time of $2.5 \mathrm{~s}$ using a conventional tool with a $1.2 \mathrm{~mm}$ long pin, as well as for the pinless tool, using the two different anvil materials. The net weld energies obtained by integrating the torque curves (equation (1)) are given in Table 1 for each condition, and are of the order of $3-5 \mathrm{~kJ}$ for a $2.5 \mathrm{~s}$ dwell time, which is about half that measured by $\mathrm{Su}$ et al with a $4 \mathrm{~s}$ dwell time and a $2 \cdot 2 \mathrm{~mm}$ long pin. ${ }^{18}$ With the conventional pin tool the torque curves are similar to those reported in the literature (e.g. Refs. 16, 18 and 23). The torque initially increases rapidly until the target shoulder plunge depth has been achieved. The curves then fall off as the sheets heat up and material loss occurs through wear and flash production, ${ }^{16,34}$ before suddenly dropping again as the tool is withdrawn. It has been suggested that melt wear ultimately limits the torque achieved. ${ }^{16,34}$ In Fig. 4 it can be noted that the curves for the pinless tool exhibit a much sharper peak in torque, due to the abrupt touch down of the tool shoulder surface, compared to the more progressive increase in contact area when a probe first penetrates the top sheet. However, although the peak torque is slightly higher, the curves then fall off more rapidly, giving a 
lower net weld energy. The weld energies in Table 1 also reflect this trend and the average values of torque and weld energy increase with pin length.

The increase in torque with pin length is related to the greater contact surface area when the probe penetrates the sheets. Su et al. have pointed out that with a conventional pin tool the tool shoulder only starts to generate heat once material extruded from the pin keyhole becomes trapped between the shoulder and the surface of the upper sheet. ${ }^{16}$ Partitioning of heat generation between the shoulder and the pin thus also depends on the dwell time and changes in favour of the pin to the shoulder for shorter pins and longer dwell times. ${ }^{18,24}$ In thicker $6.3 \mathrm{~mm}$ sheet with a $2 \cdot 2 \mathrm{~mm}$ pin the weld energy input generated by the pin has been estimated to be $\sim 70 \%$ of the heat input. ${ }^{18}$ In line with these results, with the thinner gauge sheet and shorter pin used here, the pinless tool developed a heat input of $\sim 40 \%$ less than the standard $1.4 \mathrm{~mm}$ long pin tool (Table 1).

A general decrease in torque and weld energy can be noted when the ceramic Macor anvil was used (Fig. 3, Table 1), which becomes more significant as the pin length increases, rising from $10 \%$ with no pin to $\sim 25 \%$ with the longest pin. This trend is linked to an overall increase in weld temperature (see below), owing to lower rates of heat loss form the thin sheet to the supporting anvil, which leads to a decrease in material flow stress in the shear zone and consequently a reduction in torque. $\mathrm{Su}$ et al. have also noted lower weld energy when insulation is used. ${ }^{18}$

In Fig. 5 typical thermal histories are shown recorded by the thermocouple in direct contact with the bottom surface of the lower sheet, as a function of pin length, with and without an insulated anvil. The bottom face maximum temperature rose progressively with pin length, rising from 360 to $410^{\circ} \mathrm{C}$ on increasing the pin length from 0.7 to $1.6 \mathrm{~mm}$ using the steel anvil (Fig. $5 a$ ). This behaviour is caused partly by the general increase in weld input energy with tool length. However, because the thermocouple was contacting the weld back face, it is also affected by the generation of heat deeper in the weld from plastic deformation coupled with a longer tool pin. From Fig. $5 a$ it can be further seen that there is a significant increase in peak temperatures reached by about $45-410^{\circ} \mathrm{C}$ when an insulated anvil is employed. When the ceramic insulation layer is used there is also a notable reduction in cooling rate after withdrawal of the tool, although there is little effect on the initial heating rate. The temperatures at the tool surfaces and top of the welds will of course be considerably hotter than measured at the bottom and values close to the solidus have been reported in the literature directly under the pin and tool shoulder. ${ }^{16,35}$

With the pinless tool far lower temperatures were recorded at the bottom of the weld. With a steel anvil the maximum temperature only reached $\sim 280^{\circ} \mathrm{C}$, compared to $380^{\circ} \mathrm{C}$ with a conventional $\sim 1.4 \mathrm{~mm}$ long pin. However, this again increased by $\sim 40^{\circ} \mathrm{C}$ when the ceramic anvil was used (Fig. 5). This reduction in weld temperature is partly due to the decreases in overall weld input energy (Table 1), but also because without a probe heat generation is no longer available deeper in the sheet. In Fig. 5b, the effect of weld time on the temperature cycle measured is shown for the pinless
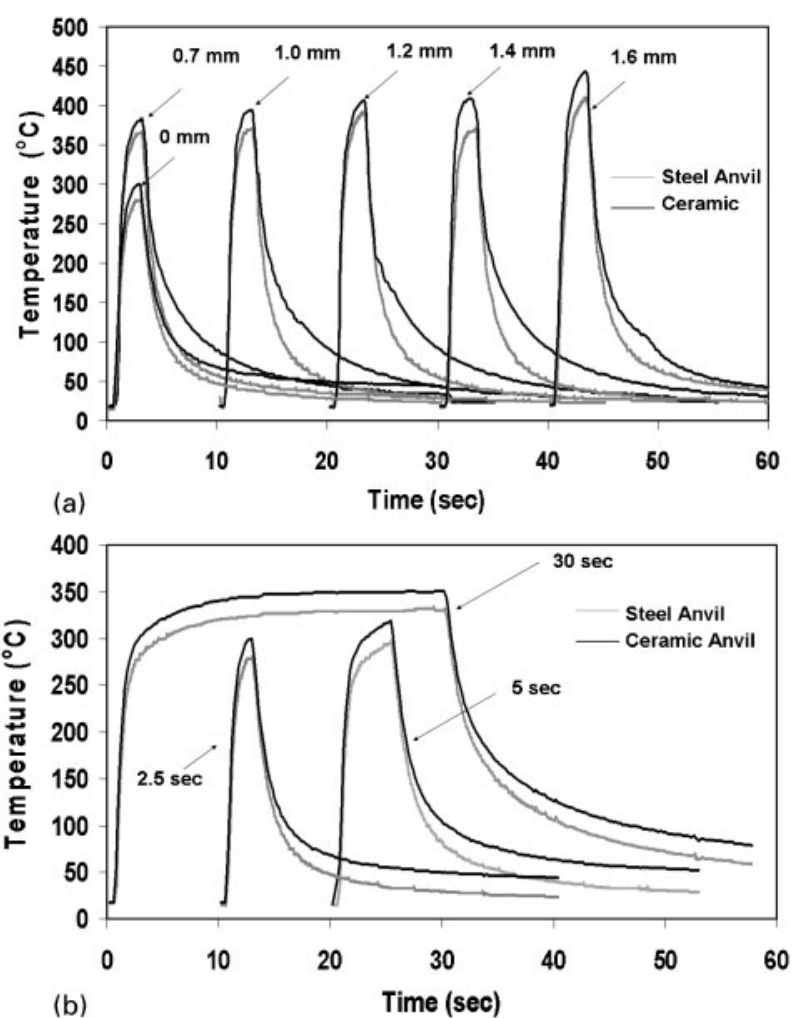

5 Typical thermal histories recorded from thermocouple in direct contact with bottom surface of lower sheet at weld symmetric centre, with and without insulated anvil, for a different pin lengths and pinless tool and in $b$ pinless tool as function of weld time (note: curves are displaced for clarity)

tool, with the different anvil materials. For short weld times the peak temperature can be seen to be very sensitive to the tool contact duration, with it taking about twenty seconds before the temperature starts to reach a steady state. Even then the peak bottom temperature is still lower than measured for the pin tool $2.5 \mathrm{~s}$ standard dwell time welds, reaching a limit of $\sim 330^{\circ} \mathrm{C}$.

\section{Lap shear fracture behaviour}

A range of failure modes have been observed in FSSW tensile lap shear tests. ${ }^{13-15,19,36}$ However, the test itself is sensitive to material thickness. When tensile shear testing spot welds in thin sheet, the joint will bend out of plane. The weld is thus not just subjected to pure shear and experiences a sheet normal tensile component, or a 'peel' force, which is greatest at the edge of the nugget. $^{36}$ This tensile component reduces with sheet thickness as the degree of bending decreases. In general terms, the failure behaviours reported for FSSWs can be separated into three main modes, the first of which has only been reported with thicker gauges $(>2 \mathrm{~mm}):^{13,19,20}$

(i) mode I: shear failure following the join line between the two sheets in the plane of the sheet ${ }^{19}$

(ii) mode II: mixed cleavage failure that initially starts by debonding, or cleavage, following the oxide debris delineating the original surfaces between the two sheets. This initiates at the edge of the shoulder contact area, where there is often only a partial bond, before turning upwards and tearing through to the top surface near the 


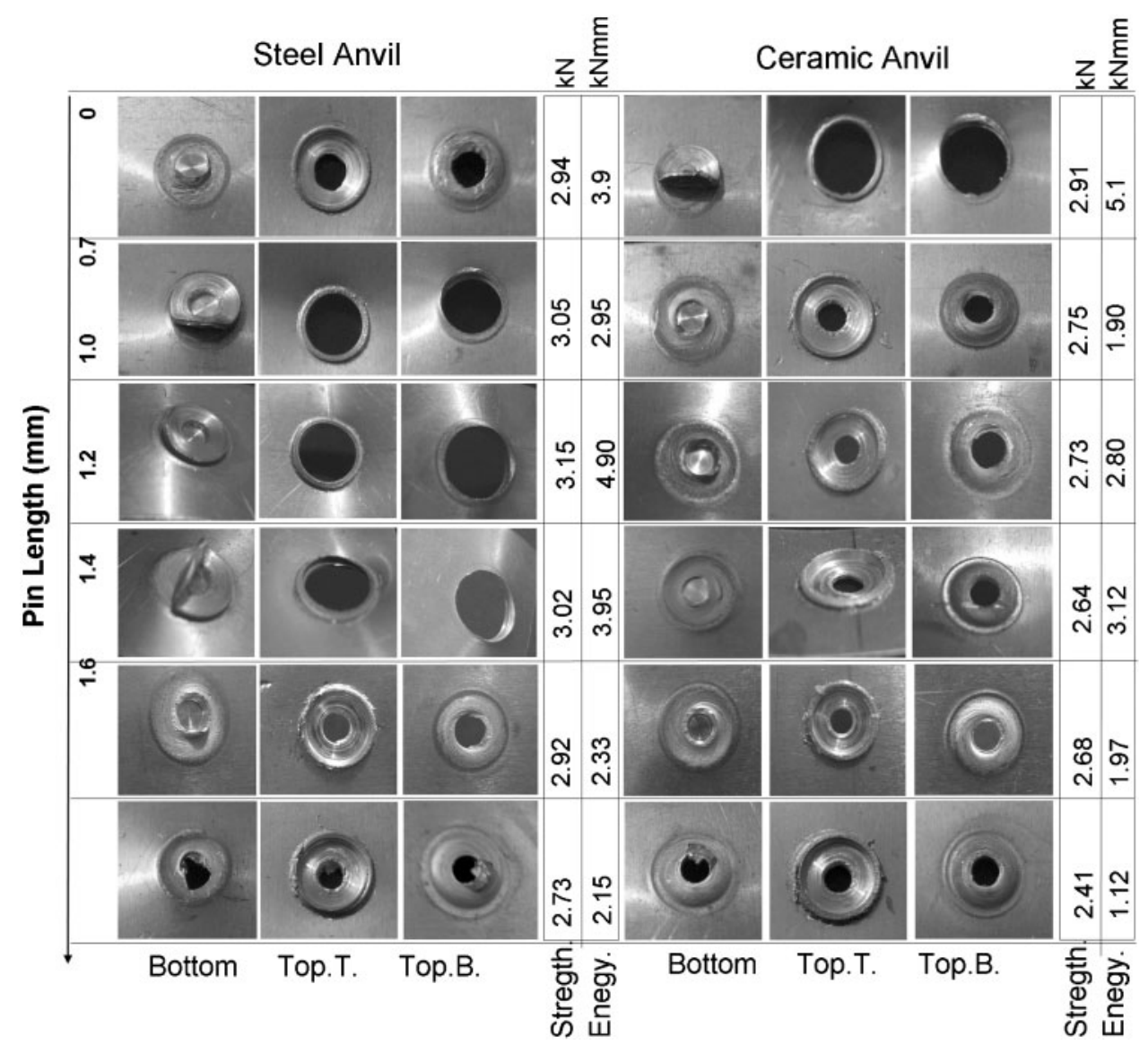

6 Examples of effect of pin length on failure mode and average strength of lap shear specimens: images shown are from fractured weld samples taken from top surface of bottom sheet and top and bottom faces of top sheet, labelled Bottom, Top.T., Top.B., respectively; corresponding fracture strengths and energies are given in $\mathbf{k N}$ and $\mathrm{kN} \mathrm{mm}^{-1}$

keyhole, where the top sheet is thinned by upward flow of the bottom sheet surface as the pin penetrates displacing material $1^{19,20}$

(iii) mode III: nugget pull out where the interface does not fail and the top sheet tears around the edge of the shoulder contact area leaving the weld nugget attached to the bottom sheet. This failure mode is also encouraged by thinning of the top sheet at the edge of the tool shoulder, due to the shoulder plunge. ${ }^{20}$

The typical fracture behaviours, after lap shear testing the welds produced with all the different welding conditions shown in Table 1, are summarised in Fig. 6, along with the corresponding average maximum load and failure energy in each case. Cross-sections through the welds before testing can be seen in Fig. 7. The appearance of the failed samples was found to be consistent with repeated tests. From comparison of the images, it can be seen that there are two distinctly different failure behaviours, corresponding to mode II, the mixed cleavage mode and mode III nugget pull out (described above). It should be noted that failure by mode III is associated with a moderately higher maximum shear strength, but a far larger fracture energy compared to mode II, as it does not involve debonding of the interface. These two failure modes thus dominate in thin sheet FSSW, where there is a substantial out of plane tensile component in the lap shear test. Which failure mode occurs in practice depends on competition between the resistance of the bond line to peel forces and the reduction in tear strength of the top sheet near the edge of the shoulder. This latter effect is caused by thinning of the top sheet from the shoulder plunge and lifting, ${ }^{14}$ which reduces the top sheet ligament width at the periphery of the shoulder (see Fig. 7), as well as from softening of the material caused by heat affected zone (HAZ) damage. A combination of these factors reduces the stress required to tear round the edge of the weld nugget. The lower strength mixed cleavage failure mode II has been far more commonly found in other studies than mode III and, with mode I, tends to dominate at thicker gauges. ${ }^{13,19,20}$

In agreement with the failure energies (Fig. 3b), Fig. 6 shows that with a steel anvil the mixed cleavage failure mode II can be seen to occur for all the welds produced with pin lengths longer than $1.0 \mathrm{~mm}$. Whereas, the strongest welds produced using the steel anvil with shorter pin lengths $(0.7$ and $1.0 \mathrm{~mm})$ failed by mode III. In comparison, the welds produced with a ceramic anvil and pin tools all failed by mode II, irrespective of pin length. Overall, the data thus lead to the conclusion that under these welding conditions an insulated anvil increases the weld temperature, but reduces the interface bond strength when a conventional pin tool is used.

For the non-insulated steel anvil tests it can be seen there is a consistent trend of change in fracture mode with increasing pin length and shear strength/failure energy (Fig. 6). For example, the strongest welds with a short $0 \cdot 7-1 \mathrm{~mm}$ pin fractured by mode III, with nugget 


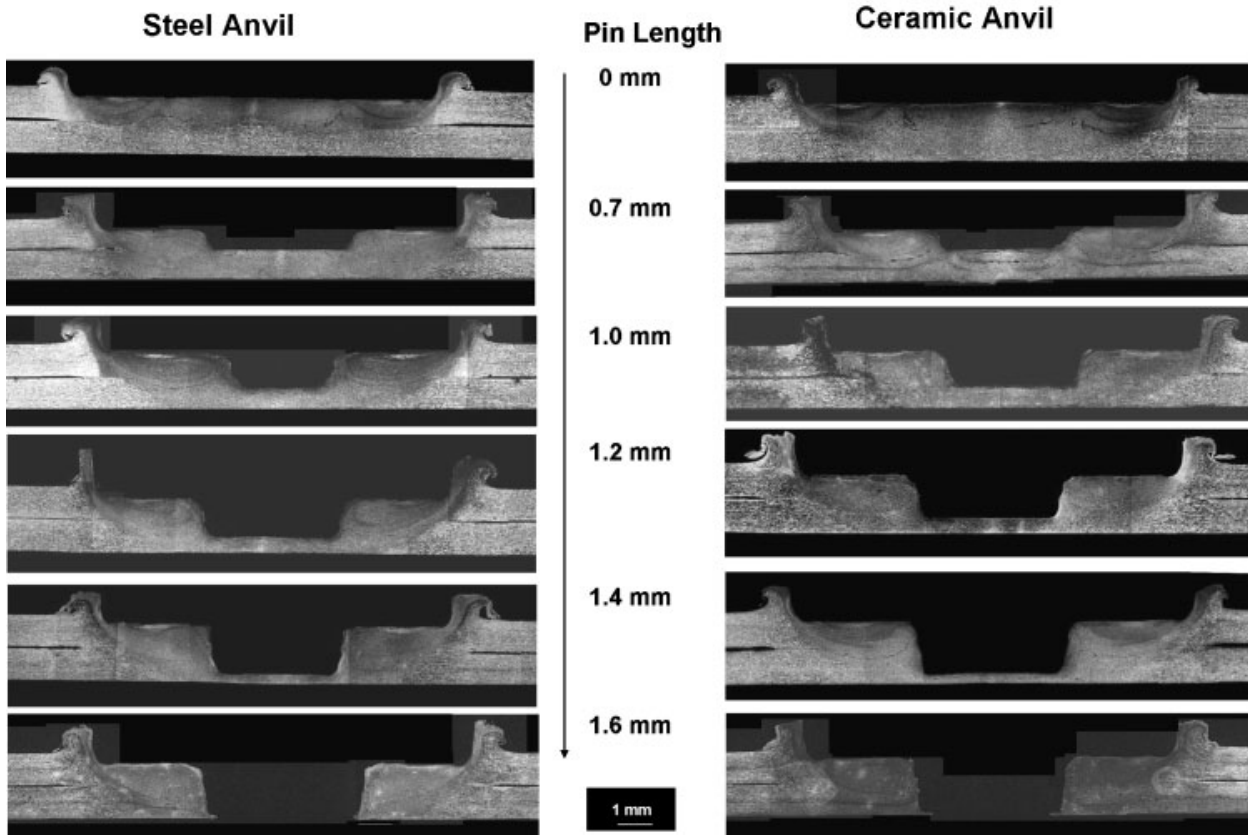

7 Optical mages of FSSW joint cross-sections in 6111-T4 sheets for different pin lengths, with and without anvil insulation

pull out leaving a fully attached disc of a similar size to the tool shoulder on the bottom sheet and the interface clearly did not fail. With the $1.4 \mathrm{~mm}$ and longer $1.6 \mathrm{~mm}$ pins the samples failed by mode II with interface debonding. However, for the intermediate $1.2 \mathrm{~mm}$ pin length it can be seen that the test coupon failed by a mixture of failure modes II and III, with the top sheet incompletely debonding before tearing around the periphery of the shoulder indent and leaving a bent partially attached nugget on the bottom sheet.

It was also observed that the mode II mixed cleavage failure leaves an increasing lip around the keyhole with greater pin length. This can best be seen in the ceramic anvil series of samples in Fig. 6 and occurs because the interface line bends up locally close to the pin, due to upward flow of the bottom sheet by the material displaced by the probe, to a degree depending on the pin insertion depth (see Fig. 7). From Fig. 7 it can further be seen that the use of a 'tight' clamping fixture has constrained lifting of the top sheet, caused by the expansion of the sheet under the shoulder as it is compressed during the tool plunge (see for example Refs. 14 and 15). This leads to a tighter joint and less top sheet thinning at the periphery of the nugget under the shoulder edge. When combined with a minimised shoulder plunge depth, this will improve the joint strength under the more desirable nugget pull out failure mode. Gross et al. have also noted the advantages of using a top clamping fixture in FSSW. ${ }^{32}$

When using the pinless tool, welds produced with the ceramic anvil failed by the higher energy fracture mode III, leaving the full weld nugget attached to the bottom sheet, or only partially debonded before nugget tear out. However, the colder welds produced with a steel anvil tended to partially debond more frequently, leaving either a partly attached or reduced diameter disc adhered to the bottom sheet, as shown in the example in Fig. 6.

\section{Weld cross-sections and interfacial bonding}

In Fig. 7, optical images are shown of cross-sections of FSSW specimens produced with different pin lengths and the two different anvil insulation conditions. From comparison of these figures, it can be seen that the weld thermomechanically affected zones (TMAZs) are similar in size, being largely controlled by the width of the tool shoulder, although the plasticised zone does not extend as far down into the bottom sheet with shorter pin lengths and the pinless tool. There is also some indication that the base of the TMAZ is deeper and slightly wider in welds produced with anvil insulation. Because the shoulder plunge depth was kept the same, there is not a great variation in the top sheet ligament thickness at the edge of the shoulder.

Of further interest is that when no pin is present the base of the plasticised zone and the bond line between the two sheets does not remain flat, but develops a wavy morphology, with a deeper outer 'doughnut' ring. This indicates that plastic deformation probably develops progressively as a function of the radial position; i.e. the material gets hottest and softest fastest under the edge of the shoulder where the radial velocity is highest and starts to deform their first. Plastic flow will then spread inwards as the temperature rises near the tool centre. It is also possible a zone of slip eventually occurs under the edge of the shoulder, if the temperature approaches the solidus $T_{\mathrm{S}}$ locally at the tool sheet interface. It is difficult to obtain direct evidence of localised melting at the contact surface, ${ }^{34}$ however, temperatures as high as 0.94 $T_{\mathrm{S}}$ have been recorded close to the tool interface in 6111 FSSW. ${ }^{16}$

In FSSW the interface between the two lapped sheets is known to typically involve regions with:

(i) a kissing bond

(ii) a partial metallurgical bond, where intermittent voids and segments of continuous interfacial oxide are still present 


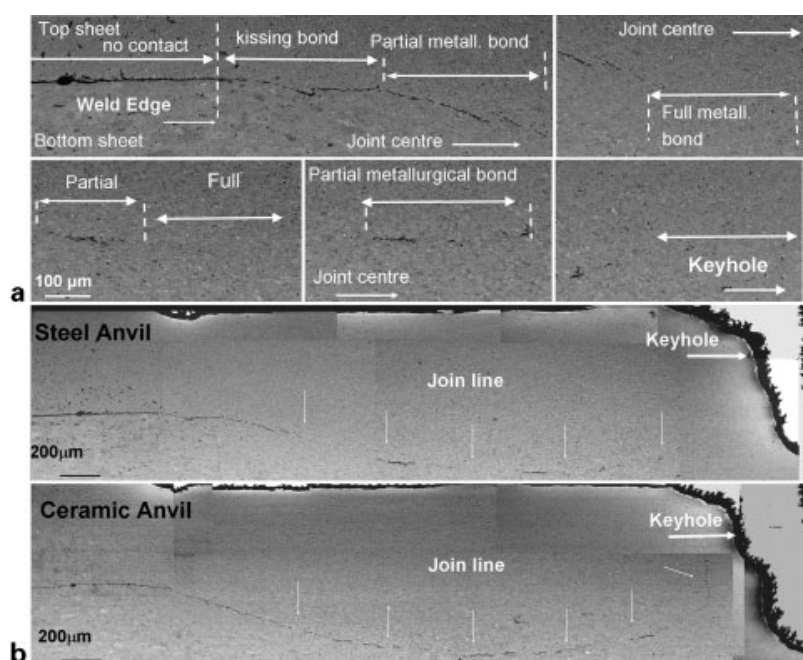

8 Images (SEM) of sections through weld bond lines $a$ at high magnification showing examples of interfacial defects and regions of characteristically different bond types (labelled) and $b$ whole weld interface, from joints produced using $1.2 \mathrm{~mm}$ pin length tool, with and without anvil insulation

(iii) a full metallurgical bond, where the oxide is dispersed and no voids remain. ${ }^{13,20}$

Examples of these different bond classifications are given in Fig. $8 a$. The strongest metallurgically bonded area will vary depending on the welding conditions. A kissing bond is frequently reported near the edge of the shoulder contact area and the larger deformation close to the pin generally results in a better metallurgical bond, by greater disruption of the interface near the weld keyhole. $^{13,20}$ As has been mentioned by Badarinarayan et al., ${ }^{21}$ the presence of interfacial oxide diminishes the quality of the friction spot welds, since crack propagation follows the oxide layer when the weld is subjected to external loading. Equally, regions of oxide at the interface are often associated with a kissing bond, or porosity, and will readily link up during crack propagation.

In Fig. $8 b$ examples of SEM images are shown of the joint interfaces for a $1.2 \mathrm{~mm}$ pin length weld, with and without anvil plate insulation, after light electropolishing to reveal the degree of bonding and oxide distribution. The estimated relative lengths of each bond type, (i)-(iii), along a section through each weld centre, are presented in Table 2 for all the welding conditions. It should be noted that the distinction between interface bond types is somewhat subjective. Nevertheless, with welds produced using a pin tool, in all cases the ceramic anvil resulted in a lower weld shear performance compared to the steel anvil (Fig. 3) and the interface between the two sheets was found to have a greater proportion of only partial metallurgical bonding, as can be seen in Fig. 8 and in Table 1. The strongest joints produced with the shorter $0 \cdot 7-1 \cdot 2$ pin lengths and a steel anvil, which failed by mode III, were also found to have the greatest proportion of the join line that had a full metallurgical bond (see Table 2).

The welds made with the pinless tool exhibited a high degree of metallurgical bonding compared to welds produced with a pin tool. Those produced with the ceramic anvil exhibited a greater average failure energy, of $5.8 \mathrm{kN} \mathrm{mm}^{-1}$, compared to $\sim 4 \mathrm{kN} \mathrm{mm}^{-1}$ using a steel anvil. This difference was again reflected in the bond line measurements, with the pinless welds produced with an insulating anvil having a very high relative metallurgical bond length of $75 \%$, which reduced to $60 \%$ when a steel anvil was used.

\section{Microstructural changes in weld zones}

A contributory factor to joint performance when FSSW a heat treatable alloy would be expected from any loss of strength of the parent material following exposure to the weld thermal cycle. It was also of interest to determine if the different tool geometries and anvil thermal properties had a detectable influence on the weld microstructure and hardness distributions. A commercially available thermodynamic database (JMatPro) ${ }^{37}$ was first used to calculate the dissolution temperatures of the equilibrium phases present in the 6111 alloy, which is a useful aid to interpretation of the weld hardness profiles and microstructures. The 6111 alloy is known to contain the $\mathrm{Q}\left(\mathrm{Al}_{5} \mathrm{Cu}_{2} \mathrm{Mg}_{8} \mathrm{Si}_{6}\right)$ and $\beta\left(\mathrm{Mg}_{2} \mathrm{Si}\right)$ phases, which were predicted to have equilibrium solvus temperatures of 440 and $540^{\circ} \mathrm{C}$, respectively. The 6111 alloy is also predicted to reach its melting point at $\sim 580^{\circ} \mathrm{C}$.

Figure 9 shows example microhardness profiles measured $0.2 \mathrm{~mm}$ below the shoulder plunge depth and above the bottom surface for welds produced with the $0.7 \mathrm{~mm}$ pin tool and a pinless tool, with and without anvil insulation. The hardness profiles across the welds with the pin tool exhibit a 'W' shape, similar to that classically seen in friction stir seam welds in comparable heat treatable alloys. ${ }^{38-41}$ At the periphery of the weld there is a large drop in hardness by $\sim 30 \%$, caused by rapid overaging, which typically occurs in the temperature range $300-400^{\circ} \mathrm{C}^{40}$ The location of the hardness minima coincide approximately with the edge of the TMAZ, and have been observed in a similar position in FSWs. ${ }^{38-41}$ Furthermore, directly under the tool shoulder, recovery in strength occurs as the

Table 2 Estimates of relative lengths of kissing, partial and full metallurgical bonding along join line, measured from cross-sections through centre of spot welds, for pinless and conventional pin tools, with and without anvil insulation

\begin{tabular}{|c|c|c|c|c|c|c|}
\hline \multirow[b]{2}{*}{ Pin length, mm } & \multicolumn{3}{|l|}{ Steel anvil } & \multicolumn{3}{|c|}{ Ceramic anvil } \\
\hline & Kissing, \% & Partial, \% & Full, \% & Kissing, \% & Partial, \% & Full, \% \\
\hline Pinless & 12 & 28 & 60 & 6 & 19 & 75 \\
\hline $0 \cdot 7$ & 9 & 42 & 58 & $8 \cdot 5$ & 47 & 45 \\
\hline $1 \cdot 0$ & 13 & 23 & 64 & 20 & 58 & 42 \\
\hline $1 \cdot 2$ & $8 \cdot 6$ & 39 & $52 \cdot 4$ & $8 \cdot 2$ & 68 & $23 \cdot 8$ \\
\hline $1 \cdot 4$ & $17 \cdot 7$ & $61 \cdot 3$ & 21 & 18 & 68 & 14 \\
\hline $1 \cdot 6$ & $3 \cdot 3$ & $35 \cdot 4$ & $61 \cdot 3$ & $3 \cdot 3$ & 85 & $11 \cdot 7$ \\
\hline
\end{tabular}



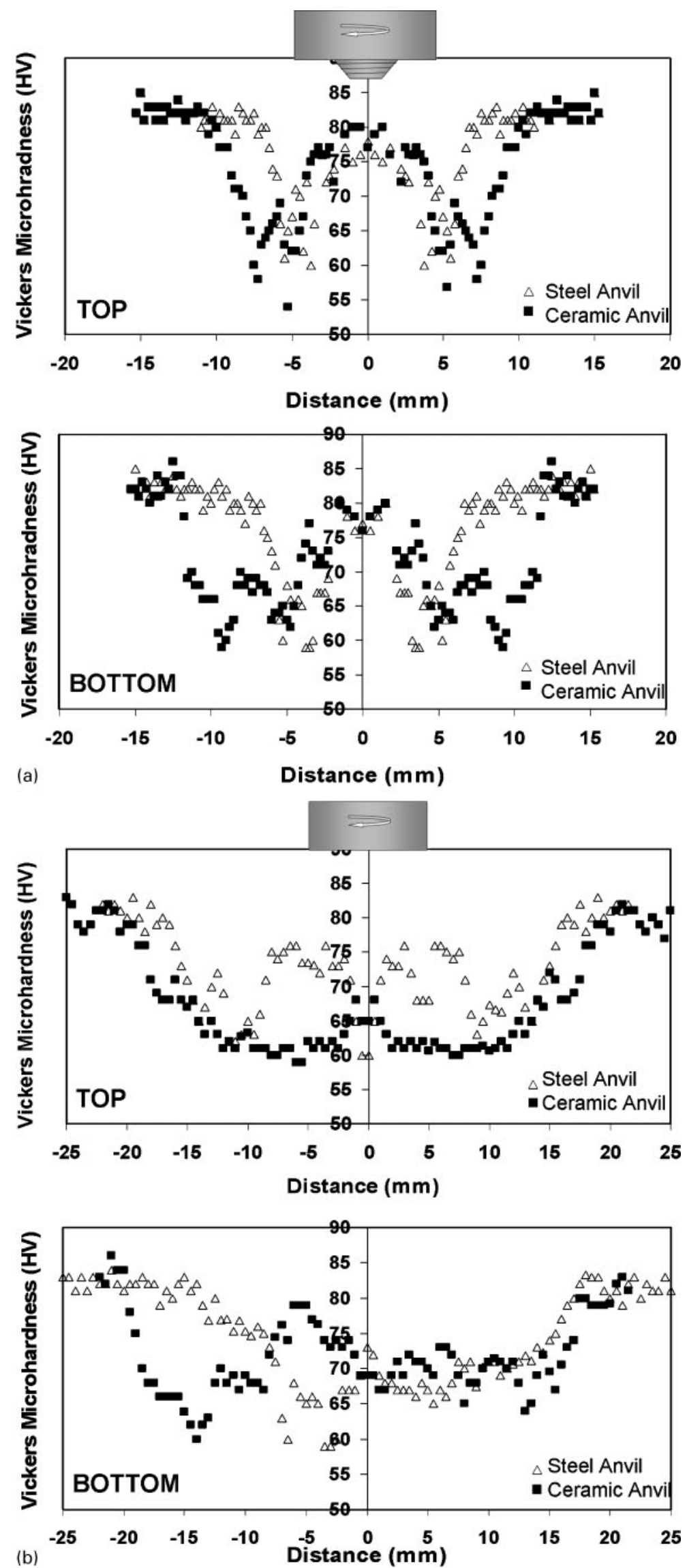

9 Top and bottom microhardness profiles, through weld centres, for friction stir spot welds produced with a 0.7 pin length and $b$ pinless tool: hardness traverses were performed $0.2 \mathrm{~mm}$ below and above top and bottom surface respectively 
temperatures reaches levels high enough for solution treatment and subsequent post weld natural aging. ${ }^{39,41}$ To obtain a substantial natural aging response, the $\beta$ phase solvus must have been approached and this suggests that peak temperatures in this position were of the order of $\sim 540^{\circ} \mathrm{C}$. The recovery in yield stress is noticeably less at the bottom of the weld, where the temperature is lower, resulting in a lower level of solutionisation. It can be further seen the HAZ expands sideways and the hardness minima at the TMAZ/HAZ boarder became deeper when the ceramic anvil was used. The increase in HAZ width is greater at the bottom of the weld, where the insulated anvil would be expected to have more effect. The insulated anvil also results in a greater level of post weld natural aging near the weld bottom, consistent with the $\sim 45^{\circ} \mathrm{C}$ higher temperature measured on the back face of the welds produced with a ceramic anvil.

In comparison, the hardness profiles from the welds produced with a pinless tool (Fig. 9b), which were measured to have a $\sim 100^{\circ} \mathrm{C}$ lower back face peak temperatures and dissipated less weld energy, show clear evidence of lower peak temperatures throughout the weld zones, but most significantly at the weld base. In Fig. $9 b$ the hardness profiles indicate little post weld natural aging occurring, either at the top or bottom, of the weld produced with the steel anvil, suggesting that the temperatures were substantially below $540^{\circ} \mathrm{C}$ and did not exceed that required for significant solutionisation. With the ceramic anvil some hardness recovery is observed near the weld centre in the top sheet, but again little is seen at the weld base.

The hardness profiles correlated closely to the distribution of coarse overaged precipitates within the welds. In Fig. 10, SEM images of the microstructures at the top and bottom of the welds, at a radial distance of $3.5 \mathrm{~mm}$ from the weld centre, confirm an increase in temperature with pin length and the use of a ceramic anvil. It is evident that a lower density of coarse precipitates is generally seen near the hotter, weld top, where the soluble second phases are mostly dissolved. From the higher volume fractions of coarse second phase precipitates seen in the coldest weld, produced with the pinless tool and steel anvil, it is apparent that at the top position the maximum temperatures in this case could not have exceeded much above $\sim 450^{\circ} \mathrm{C}$. For this weld two families of precipitates were seen at the weld base; incoherent coarse spherodised precipitates and finer semicoherent laths. The lath morphology precipitates disappear at the top of the weld and are probably the $\mathrm{Q}$ phase, which has a lower solvus temperature $\left(440^{\circ} \mathrm{C}\right)$. The coarse spherodised precipitates are the $\beta$ phase. In the welds produced with the pin tools full solutionisation has occurred at the top position and only insoluble $\mathrm{Mn}$ rich dispersoids and broken up primary $\mathrm{Fe}$ rich particles remain [typically $\left.\mathrm{Al}_{12}(\mathrm{Fe}, \mathrm{Mn})_{3} \mathrm{Si}\right] .{ }^{42}$ In all cases the lath morphology $\mathrm{Q}$ phase is absent and the $\beta$ phase volume fraction decreases with pin length at the weld base. The $\beta$ phase also has a lower volume fraction at the weld base when a Macor insulated anvil is employed. A lower volume fraction of $\beta$ phase is equally seen in the welds produced with the pinless tool using the ceramic anvil. The peak temperatures in the welds produced with a pin tool must, therefore, have all been above the $\beta$ solvus at their top $\left(540^{\circ} \mathrm{C}\right)$, and were probably some $40^{\circ} \mathrm{C}$ higher at the position imaged above the weld base than indicated by the bottom surface contacting thermocouple employed in Fig. 5. The results also confirm a generally lower temperature when welding with a pinless tool or steel anvil.

Electron back scattered diffraction analysis has been used to investigate the grain structures of the spot welds. The mechanisms that result in the fine nugget grain structures typically seen in aluminium FSWs involve; grain splitting, due to orientation instability and shear banding at low temperatures as the material first enters the tool deformation zone, followed by geometric dynamic recrystallisation at high strains, strain rates, and temperatures, as the material flows around the tool. ${ }^{43,44}$ This is followed by the possibly of static recrystallisation and grain growth, as the material is left to cool in the thermal wake of the tool. ${ }^{35,43,44}$ In FSSWs, because the tool is not translated the material flow is somewhat different, ${ }^{25}$ but similar high temperatures and strain conditions are approached close to the tool surface. In Fig. 11 example EBSD maps are given at different thickness positions for the pinless tool welds. Statistical data from the EBSD maps are summarised in Table 3. It can be seen that immediately below the tool surface there is a fine low aspect ratio grain structure, but there is still a significant $\sim 40 \%$ fraction of low angle boundaries which is higher than that normally found in the nugget region of FSWs (about $70-80 \%$ ). ${ }^{43,44}$ This could imply that the material is less 'recrystallised' than in a FSW. However, other researchers have reported higher high angle boundaries (HAB) fractions in similar welds (e.g. Ref. 23) and to date there have been few systematic attempts to study how grain structures form in FSSWs and is affected by post weld cooling.

In Fig. 11 and Table 3 it can be further seen that the fraction of $\mathrm{HABs}$ decreases and the average $\mathrm{HAB}$ spacing (grain size) increases with depth. This is associated with a reduction in strain and temperature, leading to a grain structure that contains predominantly subgrains and deformed grains of a similar size to in the parent material at the bottom of the weld. In Fig. 11 it is very obvious that there is a strong effect of the insulating anvil, with a larger grain size at the top of the weld $(6 \cdot 8$ compared to $4.8 \mu \mathrm{m}$ ) and the mid position appearing more 'recrystallised' than when a steel anvil is used. This is partly due to an increase in the weld temperature, but is also as a result of the deformation zone penetrating further into the bottom sheet when there is a lower through thickness temperature gradient. The influence of the ceramic anvil is also evident in the pin tool welds where the grain size is significantly larger within the weld deformation zone (see Table 3 ).

\section{Factors contributing to joint performance in thin sheet FSSWS}

From the above experiments, in thin sheet welds $(\sim 1 \mathrm{~mm})$, it is clear that the strongest welds were obtained when failure occurs via nugget pull out (mode III), rather than by interface cleavage, or debonding, (mode II). Indeed, it could be argued that when interfacial debonding occurs a true weld has not actually been made. The main objective of friction stir spot welding thin sheets should thus be to obtain a strong enough metallurgical bond under the tool shoulder, by disrupting the oxide that naturally exists on the sheet 


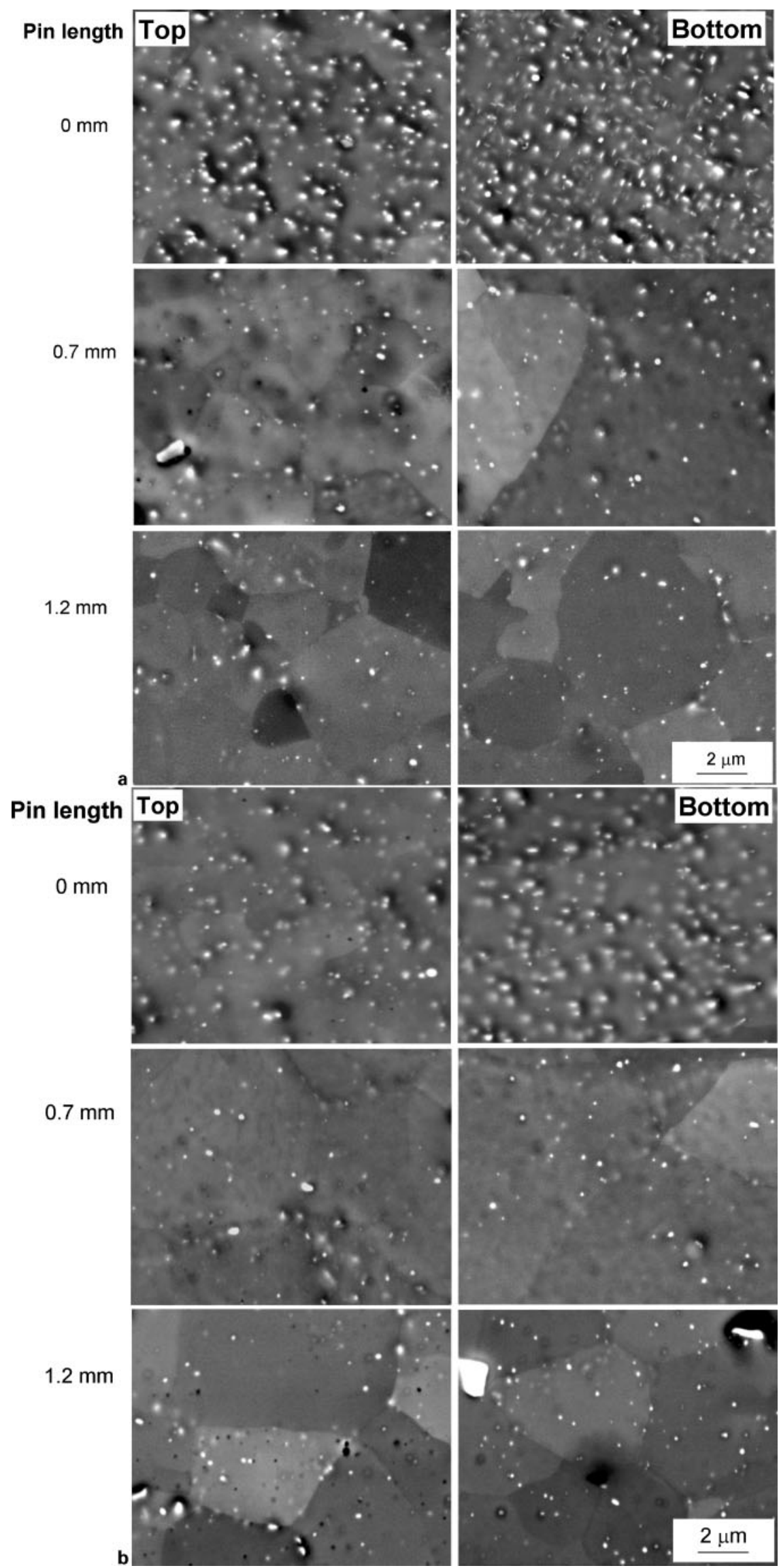

10 Images (SEM) showing coarse second phase precipitates present in weld zones, as function of pin length, at $0.2 \mathrm{~mm}$ below top and above bottom surface of welds at radial distance of $3.5 \mathrm{~mm}$ from weld centre: in a with steel anvil and in $b$ with insulated anvil 

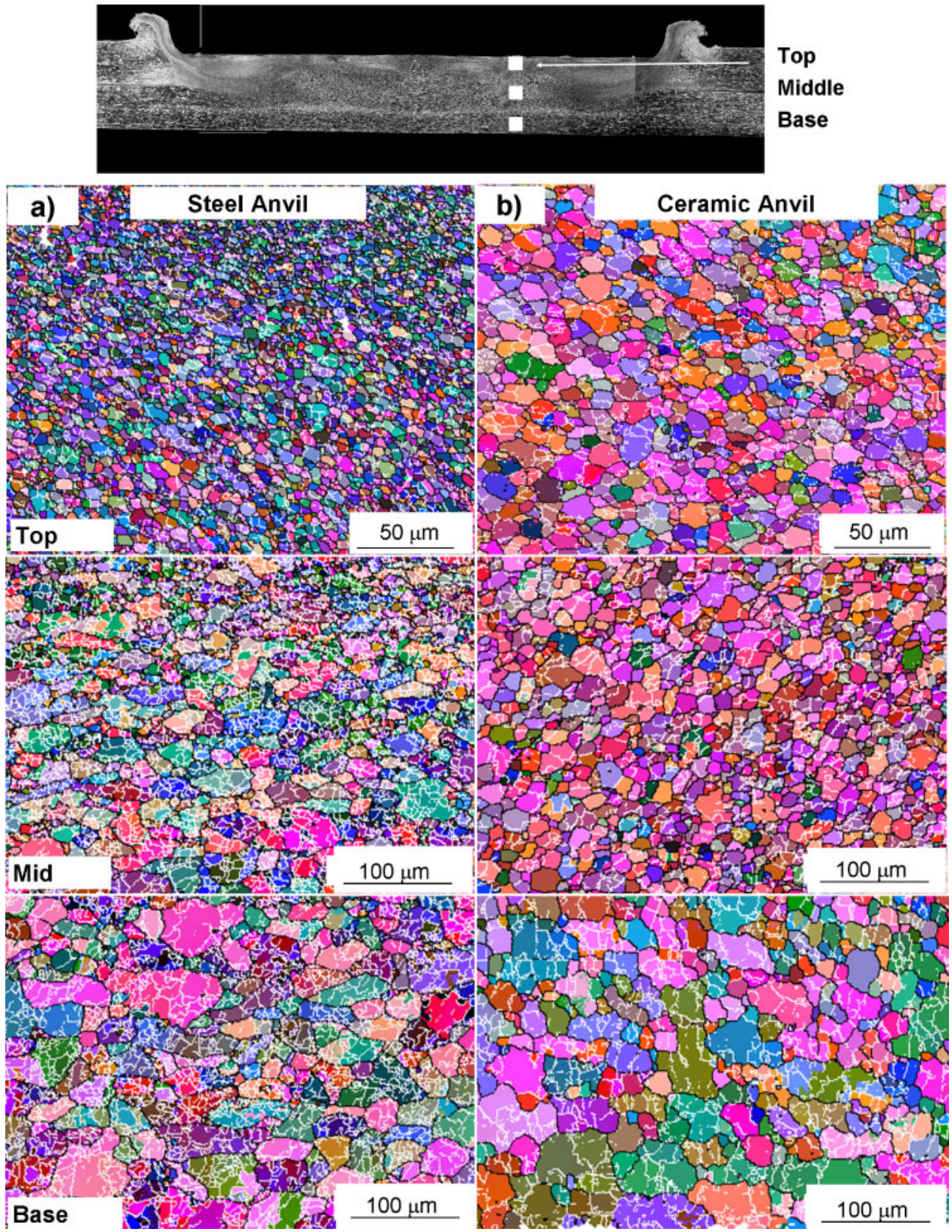

11 Example EBSD maps at different positions from pinless tool spot welds, $a$ without and $b$ with an insulating anvil: top to bottom positions correspond to: Top; just below shoulder, Middle; mid plane, Bottom; $0.2 \mathrm{~mm}$ above bottom surface, all measured through depth at a radial position of $3.5 \mathrm{~mm}$ out from weld centre (see macrograph insert); in maps black and white lines correspond to high $\left(\geqslant 15^{\circ}\right)$ and low angle boundaries respectively

Table 3 Average statistical data obtained from EBSD maps at different positions in $1.2 \mathrm{~mm}$ pin tool and pinless tool welds, with and without an insulating anvil: including average grain size (liner intercept high angle boundary spacing), average cell size (spacing of all boundaries, including low angle) and percentage fraction of high angle boundary area* (HAB \%)

\begin{tabular}{|c|c|c|c|c|c|c|c|}
\hline \multirow[b]{2}{*}{ Type of joint } & \multirow[b]{2}{*}{ Position } & \multicolumn{3}{|l|}{ Steel anvil } & \multicolumn{3}{|l|}{ Insulating anvil } \\
\hline & & Grain size, $\mu \mathrm{m}$ & Cell size, $\mu \mathrm{m}$ & HAB, \% & Grain size, $\mu \mathrm{m}$ & Cell size, $\mu \mathrm{m}$ & $\mathrm{HAB}, \%$ \\
\hline \multirow[t]{4}{*}{ 1. $2 \mathrm{~mm}$ Pin Tool } & Top & $4 \cdot 78$ & $2 \cdot 45$ & $56 \cdot 3$ & $6 \cdot 85$ & $4 \cdot 24$ & $62 \cdot 8$ \\
\hline & Middle & $5 \cdot 7$ & 3.52 & $62 \cdot 2$ & $10 \cdot 76$ & 6 & $56 \cdot 6$ \\
\hline & Bottom & 14.96 & $5 \cdot 85$ & $43 \cdot 8$ & $12 \cdot 69$ & $6 \cdot 4$ & $52 \cdot 3$ \\
\hline & Pin base & $8 \cdot 17$ & $4 \cdot 76$ & $60 \cdot 3$ & 13 & 8.09 & $64 \cdot 1$ \\
\hline \multirow{3}{*}{ Pinless tool } & Top & $3 \cdot 44$ & $2 \cdot 35$ & $69 \cdot 5$ & $6 \cdot 84$ & $3 \cdot 89$ & $58 \cdot 7$ \\
\hline & Middle & $12 \cdot 4$ & $4 \cdot 22$ & 36 & $11 \cdot 34$ & $6 \cdot 35$ & $57 \cdot 8$ \\
\hline & Bottom & $17 \cdot 3$ & $4 \cdot 83$ & 29 & 18.95 & $8 \cdot 02$ & $44 \cdot 1$ \\
\hline Parent Sheet & & $20 \cdot 37$ & $18 \cdot 39$ & $93 \cdot 6$ & & & \\
\hline
\end{tabular}

*The top to bottom positions correspond to: top, just below the shoulder; middle; mid plane; bottom, $0.2 \mathrm{~mm}$ above the bottom surface, all measured through the depth at a radial position of $3 \mathrm{~mm}$ out from the weld centre. The pin base position is directly below the pin centre with the pin tool welds. Data for the parent sheet are also given for comparison. 
surfaces, so that the parent sheet tears around the weld nugget rather than failure occurring by debonding at the weld interface. There will be an effect of too great a shoulder penetration, top sheet lifting and HAZ softening on the stress required to tear through the top sheet round the periphery of the nugget in failure mode III. However, such factors will only come into play if a strong enough metallurgical bond is first achieved to promote this failure mode. Influences such as the HAZ width, which can be altered by changing the weld thermal cycle (e.g. the section on 'Microstructural changes in the weld zones'), are thus secondary. It would be advantageous if the HAZ minimum could be engineered to not coincide with the edge of the tool shoulder, where mode III nugget pull out occurs. Furthermore, the problem of top sheet thinning near the keyhole, which has been identified as a factor affecting the strength of FSSWs by several authors (e.g. Refs. 13-15, 19 and 21), does not come into play if a failure mode III occurs.

One of the surprising conclusions from the above experiments is that, in thin sheet friction stir spot welding, a long conventional pin and a more uniform and higher weld temperature, promoted through the use of an insulated anvil, can actually produce weaker welds, because both factors lead to a poorer metallurgical bond under the tool shoulder, promoting a mode II interface cleavage failure. With the $1 \mathrm{~mm}$ thick thin sheets welded here, the optimum condition was found to be with a pin length that gave a penetration depth of the order of the top sheet thickness, although this was only slightly better than when welds were produced with no pin at all. It thus appears that in thin sheets it is possible to make better welds than with a conventional tool by using either a short pin or a pinless tool. This is clearly only possible when welding thin sheets, as the plastic zone will not penetrate deeply enough as the sheet thickness is increased to disrupt the surface oxide residue at the bond line. The possibility of producing high quality welds with a pinless tool has many advantages including, a simpler process, a far better aesthetic appearance with no retained keyhole (which may need to be subsequently filled) and the elimination of the need to use a more complex process such as the refill method. ${ }^{26}$

Why weld quality appears to improve with a short or no pin in thin sheet welding still requires further investigation into the effect of the tool geometry on metal flow and heat generation. However, a number of factors may be significant in this regard. First, with a pinless tool the tool contacts across the whole top sheet surface at the same time. This will ensure that heat is generated for a longer time under a high pressure further out under the tool shoulder than when a pin must be plunged first, giving a greater chance of bonding at the edge of the weld, critical for promoting mode III failure. Material expelled by a pin will also initially result in a less uniform pressure and a reduction in the down force locally under the edge of the shoulder, until later in the weld cycle. A further effect may be related to the vertical flow of material displaced by the probe up from the bottom sheet near the pin. In conventional welds this normally results in the weld sheet interface moving upwards near the pin. In a mode II failure, when the crack path follows the joint interface, it can then more easily tear though to the top surface as the connecting ligament length is shorter (for example see Refs. 19 and 21). This effect will be reduced with a shorter probe length that does not penetrate the bottom sheet. The significantly lower temperature in the pinless welds may also play a role by subjecting the weld interface to severe plastic deformation when the material has a higher flow stress, which is consequently more successful in breaking up the interfacial oxide. In this regard a fine balance is clearly required, as the insulated anvil improved the bond strength of the pinless welds, and there is probably an optimum weld temperature and plastic zone penetration depth necessary to achieve maximum bonding when a pinless tool is used.

\section{Conclusions}

The effect of pin length, including a novel pinless tool and anvil insulation, on the lap shear strength of FSSW welds produced in thin $(0.91 \mathrm{~mm})$ 6111-T4 aluminium automotive sheet has been studied. For the welding conditions used, it was found that the weld energy and temperature increased with tool pin length. The insulated anvil reduced the torque from the rotating tool and increased the weld temperature by $\sim 40^{\circ} \mathrm{C}$.

It has been shown that optimum shear strength is obtained by ensuring failure occurs via nugget pull out, rather than by interface cleavage, or debonding. The main objective of friction stir spot welding thin aluminium sheet should thus be to obtain a strong enough metallurgical bond under the tool shoulder so that the top sheet tears, resulting in nugget pullout, rather than the joint interface failing.

When using a pin tool it was found that anvil insulation reduced the weld shear strength. More importantly, optimum joint performance was obtained with either a very short pin that did not penetrate the bottom sheet, or by using a pinless tool aided by anvil insulation. This result has important implications for the practical application of FSSW and goes against common wisdom, where it is normally assumed the probe must penetrate at least $25 \%$ into the bottom sheet top make acceptable welds. The possibility of producing high quality welds with a short or pinless tool when FSSW thin sheets is counter intuitive, but has many advantages, including a simpler process and a better aesthetic appearance with a shallow or no retained keyhole.

Why weld quality appears to improve with a short or pinless tool in thin sheet welding still requires further investigation, but qualitatively appears to be related to the pinless tool contacting more uniformly across the tool surface, giving a greater chance of bonding under the shoulder at the edge of the weld, critical for promoting mode III failure. The reduction in vertical flow of material from the bottom sheet, which is displaced as the probe is driven, also reduces the tendency for top sheet thinning, normally seen near the weld keyhole.

\section{Acknowledgements}

This research was funded through LATEST the University of Manchester EPSRC Light alloys Portfolio Partnership (EP/D029201/1). The authors are 
grateful to Yan Huang for his assistance with the EBSD characterisation.

\section{References}

1. S. Sakaguchi: J. Light Met. Weld. Constr., 1979, 17, (3), 291-297.

2. J. Peng, S. Fukumoto, L. Brown and N. Zhou: Sci. Technol. Weld. Join., 2004, 9, 331-336.

3. B. Harsha, F. Hunt and K. Okamoto: in 'Friction stir welding and processing', (ed. R. S. Mishra and M. W. Mahoney), 235-272; 2007, Metals Park, OH, ASM International.

4. T. A. Barnes and I. R. Pashby: J. Mater. Process. Technol.., 2000, 99, (1-3), 62-71.

5. T. A. Barnes and I. R. Pashby: J. Mater. Process. Technol., 2000, 99, (1-3), 72-79.

6. R. Jahn, R. Cooper and D. Wilkosz: Metall. Mater. Trans. A, 2007, 38A, 570-583.

7. R. Sakano, K. Murakami, K. Yamashit, T. Hyoe, M. Fujimoto, M. Inuzuka, Y. Nagao and H. Kashiki: Proc. 3rd Int. FSW Sym., Kobe, Japan, September 2001, TWI, CD-ROM.

8. T. Iwashita: 'Method and apparatus for joining', US patent no. 6601751, 2003.

9. J. Mortimer: Int. J. Ind. Robot, 2004, 31, (5), 423-428.

10. W. M. Thomas, E. D. Nicholas, J. D. Needham, M. G. Murc, P. Temple-Smith and C. J. Daws: 'Friction welding', GB patent application no. 9125978.8, 1991; US patent no. 5460317, 1995.

11. R. Hancock: Weld. J., 2004, 83, (2), 40.

12. Mazda: the Aluminium Association, http://www.aluminium.org/AM/ Template.cfm?Section $=$ Home\&template $=/ \mathrm{CM} / \mathrm{HTMLDisplay.cfm} \&$ ContentID $=21167$

13. D. Mitlin V. Radmilovic, T. Pan, J. Chen, Z. Feng and M. L. Santella: Mater. Sci. Eng. A, 2006, A441, (1-2), 79-76.

14. P. C. Lin, J. Pan and T. Pan: Int. J. Fatigue, 2008, 30, (1), 74-89.

15. P. C. Lin, J. Pan and T. Pan: Int. J. Fatigue, 2008, 30, (1), 90-105.

16. A. Gerlich, P. Su and T. H. North: J. Mater. Sci., 2005, 40, 64736481 .

17. A. Gerlich, P. Su and T. H. North: Metall. Mater. Trans. A, 2006, 37A, 2773-2786.

18. P. Su, A. Gerlich, T. H. North and G. J. Bendzsak: Sci. Technol. Weld. Join., 2004, 11, 163-169.

19. Y. Tozaki, Y. Uematsu and K. Tokaji: Int. J. Mach. Tools Manuf., 2007, 47, (15), 2230-2236.

20. D. Bakavos and P. B. Prangnell: Proc. 7th Int. FSW Sym., Awaji Island, Japan, May 2008, TWI, CD-ROM.

21. H. Badarinarayan, Q. Yang and S. Zhu: Int. J. Mach. Tools Manuf., 2009, 49, 142-148.

22. K. Okamoto, F. Hunt and S. Hirano: 'Development of friction stir welding technique and machine for aluminum sheet metal assembly - friction stir welding of aluminum for automotive', SAE Technical Series 2005-01-1254, 2005.
23. A. Gerlich, P. Su, M. Yamamoto and T. H. North: J. Mater. Sci. 2007, 42, 5589-5601.

24. P. Su, A. Gerlich, T. H. North and G. J. Bendzsak: 'Energy generation and stir zone dimensions in friction stir spot welds', SAE Technical Series 2006-01-0971, 2006.

25. M. Wang, V. H. Mucino, Z. Feng and S. A. David: 'Modeling of friction stir spot welding process', SAE Technical Series 2005-011251, 2005.

26. C. Schilling C and J. F. dos Santos: 'Method and device for joining at least two adjoining work pieces by friction welding', US patent no. $6722556 \mathrm{~B} 2,2004$.

27. M. Tier1, T. Rosendo, C. W. Olea, C. Mazzaferro, F. D. Ramos, M. Bayer, J. F. dos Santos, A. A. M. da Silva, J. Mazzaferro and T. R. Strohaecker: Proc. 7th Int. FSW Sym., Awaji Island, Japan, May 2008, TWI, CD-ROM.

28. Y. Uematsu, K. Tokaji, Y. Tozaki, T. Kurita and S. Murata: Int. J. Fatigue, 2008, 30, 1956-1966.

29. A. C. Addison and A. J. Robelou: Proc. 5th Int. FSW Sym. Metz, France, September 2004, TWI, CD-ROM.

30. B. M. Tweedy: Proc. 7th Int. FSW Sym., Awaji Island, Japan, May 2008, TWI, CD-ROM.

31. K. Miyagawai, H. Matsumural, T. Yasui, M. Tsubaki and M. Fukumoto: Proc. 7th Int. FSW Sym., Awaji Island, Japan, May 2008, TWI, CD-ROM.

32. J. Gross, B. Tweedy and C. Widener: 'Development of an endeffector for friction stir spot welding', SAE Technical Series, 200801-2286, 2008.

33. Y. Huang and F. J. Humphreys: Mater. Charact., 2001, 47, 235 240.

34. A. Gerlich, M. Yamamoto and T. H. North: J. Mater. Sci., 2008, 43, 2-11.

35. A. Gerlich, M. Yamamoto and T. H. North: Metal. Mater. Trans., 2006, 38, (6), 1291-1302.

36. Y. Uematsu and K. Tokaji: Sci. Technol. Weld. Join., 2009, 14, (1) 61-71.

37. http://www.thermotech.co.uk/consult.html

38. R. S. Mishra and Z. Y. Ma: Mater. Sci. Eng. R, 2005, R50, (1-2), $1-78$.

39. A. Sullivan and J. Robson: Mater. Sci. Eng. A, 2008, A478, (1-2), 351-360.

40. N. Kamp, A. Sullivan and J. D. Robson: Mater. Sci. Eng., 2007, 467, (1-2), 246-255.

41. Kh. A. A. Hassan, P. B. Prangnell, A. F. Norman, D. A. Price and S. W. Williams: Sci. Technol. Weld. Join., 2003, 8, 257-268.

42. J. T. Staley: Proc. 3rd Int. Conf. on 'Aluminum alloys', Trondheim, Norway June 1992, The Norwegian Institute of Technology and SINTEF Metallurgy, 107-143.

43. P. B. Prangnell, C. P. Heason and K. J. Colligan: Int. J. Offshore Polar Eng., 2004, 14, 289-295.

44. P. B. Prangnell and C. P. Heason: Acta Mater., 2005, 53, 3179 3192 